\title{
Phenomenology of the creep process of a precipitation-hardenable AlMgSi alloy wires for overhead power lines. Experimental tests. Simulation
}

\author{
Tadeusz Knych • Andrzej Mamala • Beata Smyrak
}

Received: 15 February 2007 / Accepted: 4 February 2009 / Published online: 19 February 2009

(c) The Author(s) 2009. This article is published with open access at Springerlink.com

\begin{abstract}
The article presents the results of the experimental test on the creep process of AlMgSi alloy wires (series 6xxx) under the conditions of variable stress. A theoretical analysis of equivalency rheological results of stress and temperature changes by means of Bayley-Norton function, which describes well the low-temperature aluminum alloys creep, was carried out. Therefore, the described issue became one-dimensional. On the basis of experimental tests, it has been proved that negative gradients of stress and temperature may generate three types of rheological behaviour, such as: Temporary decrease of creep speed (type 1), Temporary stop of creep deformation ('dead' time)—type 2 and reverse after creep (type 3).
\end{abstract}

The applicable nature of tests is placed in overhead power lines, which undergo cyclical stress- and time-dependent operation. Such a nature of conductor operation creates favourable conditions to decrease creep intensity, whereas its history and value and speed of stress and temperature lowering decide whether conductor rheological activity loss will take place. The actual material parameter controlling the conductor rheological behaviour is stress and temperature rheological equivalent. The article contains exemplary results of current-carrying capacity changes of AlMgSi alloy conductor on a given temperature range, and the calculations include actual creep characteristic and cumulated rheological inactivity caused by negative gradients of stress and temperature.

Keywords Creep · Rheology $\cdot$ Dead time $\cdot$ Rheological equivalent $\cdot$ Rheological inactivity · Rheological behavior · Low temperature creep · Creep in trend of leap stress decrease $\cdot \mathrm{AlMgSi} \cdot$ Alloy wires $\cdot$ Aluminium alloys $\cdot$ AlMgSi, overhead lines $\cdot$ Power lines, aluminium conductor $\cdot$ Heat treatability alloys $\cdot$ ACSR $\cdot$ AAAC $\cdot$ Secondary creep $\cdot$ Primary creep · Regress state · Alloys 6xxx · Wire · Aluminium wires · Heat capacity · New conductors $\cdot$ Stress change $\cdot$ Temperature change

T. Knych · A. Mamala $\cdot$ B. Smyrak (凶)

University of Science and Technology (AGH), Krakow, Poland

e-mail: smyrak@agh.edu.pl 


\section{Introduction}

The need to carry research on $\mathrm{AlMgSi}$ alloy wires creep process results from the fact that they are used for construction of self-supporting overhead aerial power line conductors. One of the aspects of operational behaviour of such conductors is permanent length increases leading to continuous lowering of tension force and as result the conductor being nearer the ground. And for that reasons the permissible value of a 10-year creep has been established by the International Electrotechnical Commission at the level of $0.5 \%$. This limit applies to all types of alloy conductors and aluminium steel conductors. For the construction of homogeneous construction made of aluminium wires the permissible value of a 10-year creep amounts to $0.8 \%$, and for aluminium and steel conductors $-0.7 \%$. Although both resistance properties and creep characteristics of aluminium, alloy and steel are different in the cited document, it has been assumed that from the rheological point of view alloy conductors and steel and aluminium conductors should be identical.

Coreless conductors hanged in a span overhead power lines undergo creep process what results in lowering of tension forces, increasing of conductor sag and in danger of electrical breakdown to earth. The ability to estimate permanent length increases of rheological origin is thus one of the most important elements of line design process. Conductor creep takes places under the conditions of permanent and cyclical tension force changes, which, for fixed span length, depends on temperature and is controlled by the conductor sag state equation. This fact in connection with material features of AlMgSi alloy may be significantly used to steer the rheological process. In particular it concerns the phenomenon which consists in temporal stop of rheological activity of material undergoing negative stress and temperature gradients. In the subject literature there is a phenomenon of reverse known sometimes as recovery creep and even as backward creep, which some authors relate to evolution of elastic modulus which takes place directly after unloading of material in creep stage. This phenomenon is regarded as material curiosity, when rheological inactivity may, depending on history and temperature and the mechanical state of material, reach thousand of hours (Smyrak 2006; Smyrak et al. 2005; Harvey and Larson 1970), this state is the same as "dead time", during which there are no permanent length increases of mechanically loaded material.

Therefore considerations over creep process carried out in relation to overhead power lines must include time changeability of stress and temperature. In particular it applies to negative gradients, and the theoretical considerations include the fact that, according to the logics of span, the increase of conductor temperature is accompanied by stress decrease and vice versa. Although independent influence of these parameters on the creep process is known, yet in the face of the fact that their negative gradients may lead to lowering, and even temporary stop of rheological processes, such questions arise: Is there a possibility to control creep process of conductors hanged in overhead power lines, if yes-in what way? And: Will skillful use of such a possibility allow for the creation of a dynamic model to control current-carrying capacity, what would be really desirable in the face of growing energy demand and breakdown dangers such as blackouts, with the world tendency to limit the constructions of new and development of already existing lines?

\section{Analysis of the subject matter}

As usual, the creep process is carried out under conditions of constant load and temperature. However, we deal with creep also under conditions of variable $\sigma$ and $T$ values. Whereas, as 
long as the increase of values of specified parameters taking place during the process leads to its intensification, the drop of any of them causes an opposite action and it may result in temporary stop of the process (Smyrak 2006; Smyrak et al. 2005; Roest 1969).

In the subject matter literature, creep is a wide process, which is at the same time well characterised. Already the works of Andrade (1910), Norton (1929), Odqvist (1966) define and describe creep in full detail, and this is further continued in application works devoted to high temperature rheological processes. On the other hand, low temperature processes, the classical example of which is creep of conductors hanged in overhead power lines, are the mainstream interest of teams in international institutions and centres such as CIGRE, IEEE, EPRI, Alcoa, which are interested in applied aspects of rheology in designing and in researches of conductor operational features. In particular we encounter their characteristics of wire and conductor creep, creep models (Bradbury et al. 1975) as well as recommendations and exploitation limits, such as a 10-year conductor creep perceived as the main indicator of material creep resistance (IEC 1597-1995). In that respect an issue of steering conductor rheological behaviour, controlled by change of stress and temperature changes seems of particular interest. In the works of Harvey $(1960,1970)$ there are characteristics of aluminium steel supported conductor creep after drop stress, which, as it turns out, leads to temporal stop of creep process. The author (Sandell 1961) points out to the possibility of obtaining the same conductor creep deformation value under the operation of equivalent stress and temperature pairs. At the same time, according to Fig. 1, it can be seen that in case of load decrease by 50\%, the creep process stopped for about 10,000 hours.

Thus skillful steering of creep process, by suitable change of stress and (or) temperature may lead to temporal inactivity of material rheological features. This observation creates possibilities to optimise the technology of conductor assembly, directed at power maximisation of transfer lines without the risk of occurrence of uncontrolled rheological phenomena.

The possibility to steer rheological potential, mentioned in these works, enforces the need to carry out not only experimental be tests, but theoretical analysis of creep process

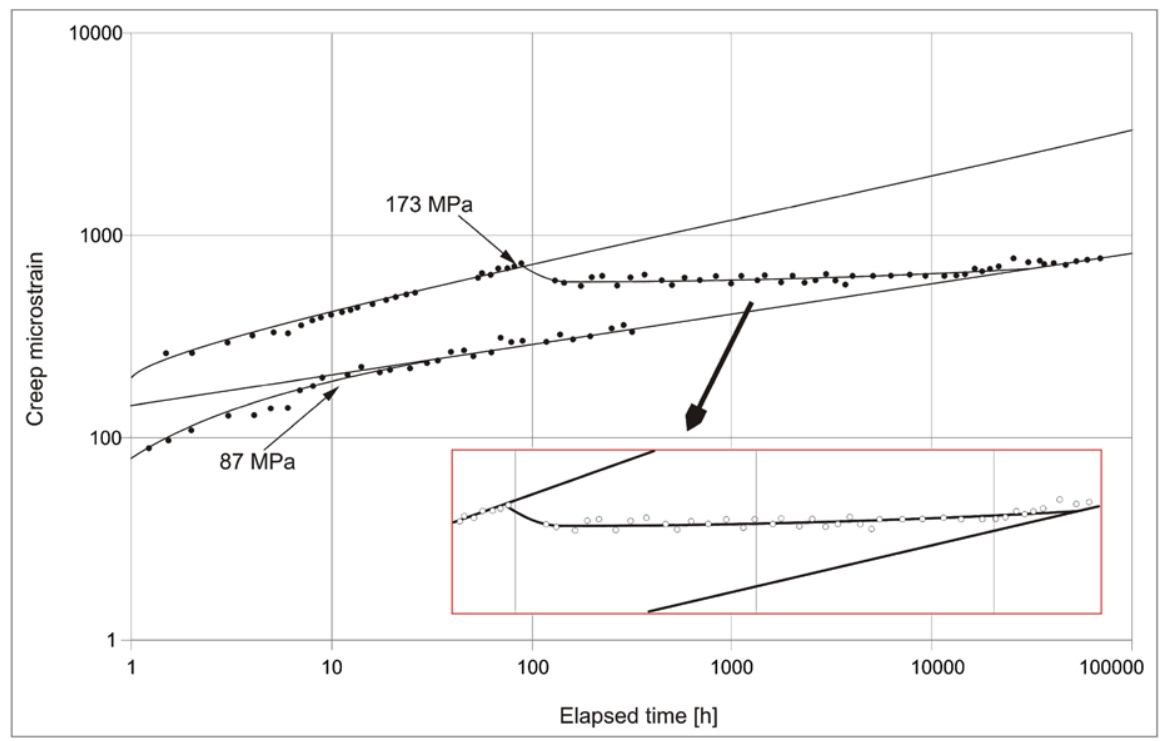

Fig. 1 ACSR (Aluminium Conductor Steel Reinforced) creep characteristic. Primary creep-stress $173 \mathrm{MPa}$ (60\%UTS) time—93 h, secondary creep—stress 87 MPa (30\%UTS) (IEC 1597-1995) 
under the conditions of changeable stress and temperature as well. Among many attempts to describe that issue, of the greatest importance are here rheological hypotheses, and among them ageing hypothesis (Penny and Marriott 1971) describing creep speed as function of stress, temperature and exposure time. This theory describes well creep under the conditions of changeable stress, but only for fixed states. Yet, it does not include transition periods, which occur at abrupt and substantial load changes. Similar situation can be found in the case of reinforcement hypothesis according to which creep speed is the function of stress and creep deformation (Penny and Marriott 1971). A more general approach to creep process description was presented by Rabotnov (1970). It is assumed that creep speed is the function of stress and structure parameters, which can characterise some phenomena taking place in material during creep, and in particular reinforcement and recovery. These hypotheses, based on such assumption, describe transition states and secondary effects caused by e.g. substantial load decrease. The third description group of creep process under changeable stress comprise hereditary hypotheses (Rabotnov 1970), among which there are linear and non-linear variants. The basis of linear hereditary hypothesis is the Boltzman superposition principle (Boltzman 1876), which assumes that tested materials have linear visco-elastic properties.

\section{Material rheological equivalent}

The four dimension Bayley-Norton numerical characteristics can be adopted as commonly acknowledged model of low temperature creep of AlMgSi alloy wires. The form is as follows:

$$
\varepsilon_{p}=\alpha_{0} \sigma^{n} \mathrm{e}^{\varphi \mathrm{T}} \tau^{\beta}
$$

where $\sigma, T, \tau$ are stress, temperature and exposure time respectively, $n, \varphi, \beta$ are material constants and $\alpha_{0}$ is an one-hour creep per one stress unit at the temperature of $0^{\circ} \mathrm{C}$. The search of rheological equivalent pairs $\sigma, T$, i.e. such stress and temperature values, which ensure the same value of creep deformation after the same process duration for that same material, is interesting not only from a mathematical point of view. Using the expression (1), in general, rheological equivalent may be presented in the following equality:

$$
\alpha_{0} \sigma_{1}^{n} \mathrm{e}^{\varphi T_{1}} \tau_{1}^{\beta}=\alpha_{0} \sigma_{2}^{n} \mathrm{e}^{\varphi T_{2}} \tau_{2}^{\beta} .
$$

Describing the identity of creep deformation in two independent attempts of the same material under the conditions of $\sigma_{1}, T_{1}, \tau_{1}$ (attempt 1) and $\sigma_{2}, T_{2}, \tau_{2}$ (attempt 2).

Taking into consideration two independent creep processes, on the basis of (2), the following alternatives can be obtained

$$
\begin{aligned}
& \left(\frac{\sigma_{1}}{\sigma_{2}}\right)^{n}=\mathrm{e}^{\varphi\left(T_{2}-T_{1}\right)}\left(\frac{\tau_{2}}{\tau_{1}}\right)^{\beta} \\
& T_{2}-T_{1}=\frac{n}{\varphi} \ln \left(\frac{\sigma_{1}}{\sigma_{2}}\right)+\frac{\beta}{\varphi} \ln \left(\frac{\tau_{1}}{\tau_{2}}\right)
\end{aligned}
$$

and

$$
\left(\frac{\tau_{1}}{\tau_{2}}\right)^{n}=\mathrm{e}^{\varphi\left(T_{2}-T_{1}\right)}\left(\frac{\sigma_{2}}{\sigma_{1}}\right)^{\beta} .
$$


Expression (3) will be called temperature-time equivalent of stress change form value $\sigma_{1}$ to $\sigma_{2}$, expression (4) stress-time equivalent of temperature change from value to $T_{2}$ to $T_{1}$, and (5) stress-temperature equivalent of creep process duration change. This special case still remains the situation where $\tau_{1}=\tau_{2}$. This assumption transforms (3)-(5) in the form of

$$
\left(\frac{\sigma_{1}}{\sigma_{2}}\right)^{n}=\mathrm{e}^{\varphi\left(T_{2}-T_{1}\right)}
$$

describing temperature equivalent of stress change, or in equivalent form

$$
T_{2}-T_{1}=\frac{n}{\varphi} \ln \left(\frac{\sigma_{1}}{\sigma_{2}}\right)
$$

However, if we assume that $T_{1}=T_{2}$, then (3)-(5) would have the following form

$$
\left(\frac{\sigma_{1}}{\sigma_{2}}\right)^{n}=\left(\frac{\tau_{2}}{\tau_{1}}\right)^{\beta} .
$$

However, for $\sigma_{1}=\sigma_{2}$ we would have the expression

$$
T_{2}-T_{1}=\frac{\beta}{\varphi} \ln \left(\frac{\tau_{1}}{\tau_{2}}\right)
$$

Equations (6) and (7) present the classical temperature-stress equivalent of creep process. In the case when these two creep processes take place under fixed temperature and under various stresses or under fixed stress and under various temperatures, time parameter becomes the equivalent, which can be in the first case described by (8), and in the second case by (9).

Let's describe the rheological equivalent with the following calculations.

For aluminium wire in strengthened stated with the dimension of $2.5 \mathrm{~mm}$ and resistance to tension of $180 \mathrm{MPa}$ the function (1) is presented with the equation in the form (Wood 1972).

$$
\varepsilon_{p}=277 E-6 \sigma^{1.35} \mathrm{e}^{0.025 T} \tau^{0.21} .
$$

The values present in (10) are expressed: stress in [MPa], temperature in $\left[{ }^{\circ} \mathrm{C}\right]$, time in $[\mathrm{h}]$.

Let's assume the following creep process conditions:

$\sigma_{1}=60 \mathrm{MPa}$

$T_{1}=20^{\circ} \mathrm{C}$

$\tau_{1}=100 \mathrm{~h}$.

Creep deformation consistent with (10) equal $0.3 \%$.

\section{Example 1}

Let's ask for the creep process temperature (equivalent temperature), in which under the stress of $40 \mathrm{MPa}$ after $100 \mathrm{~h}$ the creep deformation will equal $0.3 \%$.

According to the formula (7) $T_{2}=42^{\circ} \mathrm{C}$.

Then, the temperature equivalent of stress decrease from the value of $60 \mathrm{MPa}$ to $40 \mathrm{MPa}$ is the temperature increase by $\Delta T=22^{\circ} \mathrm{C}$. 


\section{Example 2}

Let's assume now that stress equals $80 \mathrm{MPa}$. Then according to (7) $T_{2}$ would have to amount to $5^{\circ} \mathrm{C}$ in order to ensure the same deformation value within $100 \mathrm{~h}$. The temperature decrease by $15^{\circ} \mathrm{C}$ is the temperature equivalent of stress increase by $20 \mathrm{MPa}$.

\section{Example 3}

This time let's ask how the creep process duration would have to change so that under the stress of $50 \mathrm{MPa}$ and in the temperature of $500^{\circ} \mathrm{C}$ or under stress of $70 \mathrm{MPa}$ and in the temperature of $0^{\circ} \mathrm{C}$ in order to have the equivalent, to example 1 , the value of creep deformation, i.e. $-0.3 \%$. The time, according to (5) will be for the first case $-10 \mathrm{~h}$, for the second case- $400 \mathrm{~h}$ respectively. It means that in the first case the stress decrease by $10 \mathrm{MPa}$ is not sufficient to balance the rheological increase of temperature by $30^{\circ} \mathrm{C}$. This would result in shortening the creep process duration by $90 \mathrm{~h}$. In the second case the stress increase by $10 \mathrm{MPa}$ did not balance the rheological results of the temperature decrease to $0^{\circ} \mathrm{C}$. This resulted in the increase the creep process duration by $300 \mathrm{~h}$.

For the needs of the above presented calculations it has been assumed that the material is linear-visco-elastic (is a Boltzman body).

There are many such examples. However, the objective is to present the role of time, stress and temperature parameter in the creep process and therefore to establish grounds to define the rule of equivalent states in the creep process under the conditions of changeable stress or (and) temperature.

Applying those considerations and the result of exemplary calculations to the creep process under the conditions of changeable stress or (and temperature) we should notice that according to (8) and (9) the increases of $\sigma, T$ have shorter and their decreases longer equivalent times what results in the fact that in the second case there must appear compensational dead times $\tau_{M}=\tau_{2}-\tau_{1}$ describing the material rheological inactivity, the duration of which depends on the value and speed of stress or temperature decrease or material rheological history (Smyrak 2006; Smyrak et al. 2005; Penny and Marriott 1971; Rabotnov 1970; Cadek 1988; Garofalo 1965; Lubahn and Felger 1961). However, if this process realised under changeable stress and changeable temperature would be taking place under the scheme presented in the second case of the third examples, then the dead time would amount to $300 \mathrm{~h}$.

Summing up we should notice that it is reasonable to classify creep process from the point of view of temperature and stress changes on equivalent ones, i.e. such which take place strictly according to (3) and they are time independent. These changes do not cause any creep characteristics changes. Although both stress and temperature undergo changes, we will assume that creep process takes place according to the primary characteristics, i.e. characteristics proper for the primary values of stress and temperature. However such stress and temperature changes, which as equivalent require time parameter (described by expressions (8) and (9)) will be called non-equivalent. Depending on whether proposed changes lead to shortening or lengthening of time to keep the same value of creep deformation, we will first of all differentiate over- and then under-equivalent states. Obviously, these states lead respectively to creep process intensification or to stop of its activity. 


\section{Analysis of low temperature AIMgSi alloy wires creep process}

\subsection{Material for tests}

Creep process tests were carried out on $6101 \mathrm{AlMgSi}$ alloy wires, with the following content of alloy components: $\mathrm{Si} 0.57 \%, \mathrm{Mg} 0.58 \%$, Fe $0.19 \%$, Ti $20 \mathrm{ppm}$ obtained from the wire rod that is produced by Continuous Properzi method, after homogenising treatment in the temperature of $530^{\circ} \mathrm{C}$ and solution heat treatment (T4 state) with properties from Table 1.

\subsection{Tests programme}

1. Determination of general creep function under conditions of fixed stress and temperature values and determination of stress-temperature material rheological equivalent

2. Experimental analysis of stress gradient influence on wire creep process

3. Conductor current-carrying capacity simulation in the given temperature range, using the phenomenon of material rheological inactivity.

The parameters of test procedures are presented in Tables 3 and 4.

\subsection{Test stand}

Creep process tests were carried out in specialised isothermal chamber with temperature range from -25 to $+80^{\circ} \mathrm{C}$ with an accuracy of $\pm 0.5^{\circ} \mathrm{C}$ and with the possibility to apply load

Table 1 Chemical composition of AlMgSi alloys

\begin{tabular}{lllll}
\hline $\mathrm{Si}$ & $\mathrm{Mg}$ & $\mathrm{Fe}$ & $\mathrm{Ti}$ & $\mathrm{Al}$ \\
$\%$ & $\%$ & $\%$ & $\mathrm{ppm}$ & $\%$ \\
\hline 0.57 & 0.58 & 0.19 & 20 & rest \\
\hline
\end{tabular}

Table 2 Mechanical and electrical properties of AlMgSi wires

\begin{tabular}{lllll}
\hline $\begin{array}{l}\text { Diameter } \\
{[\mathrm{mm}]}\end{array}$ & $\begin{array}{l}\text { UTS } \\
{[\mathrm{MPa}]}\end{array}$ & $\begin{array}{l}\text { Yield strength } \\
{[\mathrm{MPa}]}\end{array}$ & $\begin{array}{l}\text { Elongation } A_{250} \\
{[\%]}\end{array}$ & $\begin{array}{l}\text { Electrical resistivity } \rho \\
{[\mathrm{n} \Omega \mathrm{m}]}\end{array}$ \\
\hline 2.90 & 341 & 300 & 6 & 31.23 \\
\hline
\end{tabular}

Table 3 Parameters of creep test

\begin{tabular}{lll}
\hline$T$ & $\sigma$ & $\tau$ \\
{$\left[{ }^{\circ} \mathrm{C}\right]$} & {$[\mathrm{MPa}]$} & {$[\mathrm{h}]$} \\
\hline 20 & 34 & 160 \\
20 & 68 & 160 \\
20 & 85 & 160 \\
20 & 102 & 160 \\
20 & 136 & 160 \\
20 & 204 & 160 \\
-5 & 68 & 160 \\
40 & 68 & 160 \\
60 & 68 & 160 \\
\hline
\end{tabular}


Table 4 Parameters of the creep in conditions of stress decrease

\begin{tabular}{llllll}
\hline Primary creep & & & & \multicolumn{3}{l}{ Secondary creep } & \\
\cline { 5 - 6 } $\begin{array}{lllll}\sigma_{1} \\
{[\mathrm{MPa}]}\end{array}$ & $\sigma_{1}$ & $\tau_{1}$ & & $\sigma_{2}$ & $\sigma_{1}$ \\
{$[\% \mathrm{Rm}]$} & {$[\mathrm{h}]$} & & {$[\mathrm{MPa}]$} & {$[\% \mathrm{Rm}]$} & \\
\hline 136 & 40 & 1 & 68 & 20 & 2.0 \\
136 & 40 & 1 & 85 & 25 & 1.6 \\
136 & 40 & 1 & 102 & 30 & 1.3 \\
136 & 40 & 1 & 120 & 35 & 1.1 \\
136 & 40 & 0.1 & 68 & 38 & 2.0 \\
136 & 40 & 0.2 & 68 & 20 & 2.0 \\
136 & 40 & 0.4 & 68 & 20 & 2.0 \\
136 & 40 & & & 20 & \\
\hline
\end{tabular}

with accuracy to $1 \mathrm{~N}$, with the displacement measure carried by dial indicator with scale of $1 \mu \mathrm{m}$. The creep test consisted in placement of wire in the chamber, equipped additionally with the unit of mechanical compensation of temperature fluctuation influence during test, in determination of temperature in chamber (and in wire), in a gravitational load with a weight with strictly described mass and in a systematic measurement of wire length increases on the basis of $1.000 \mathrm{~mm}$. Figure 2 presents the test stand.

A mechanical extensometer, equipped with dial displacement indicator produced by $\mathrm{Mi}$ tutoyo with accuracy to $0.001 \mathrm{~mm}$, was used to measure elongation. The construction of extensometer provides compensation of temperature influence. As a measurement basis of extensometer $1.000 \mathrm{~mm}$ were taken, what ensures measurement accuracy up to $0.001 \%$. The expected creep deformation value in $\mathrm{AlMgSi}$ alloy wires should not exceed 1\%o, what corresponds to elongations not longer than $1 \mathrm{~mm}$. The accuracy of displacement indicators used is $1 \mu \mathrm{m}$ and is higher than the one required by e.g. CIGRE $(2 \mu \mathrm{m})$ or IEC $(5 \mu \mathrm{m})$. Additionally, the use of mechanical dial indicators guarantees good unit stability in time and low sensitivity to temperature changes, which is necessary during long term measurements.

\section{Tests results and their analysis}

Figure 3 presents, in a logarithmic system, an overall creep characteristics set of tested wires in different, but fixed stress and temperature values. On the basis of their analysis, it is clear that creep is power function of time type $\varepsilon_{p}=\alpha \tau^{\beta}$, independent of stress and temperature in the range of changeability of these parameters, adopted for these tests.

Assuming that the overall creep function as a relation between time, stress and temperature for the tested material in the changeability range $\sigma, T$ is coherent with Bayley-Norton equation (1), we have, on the basis of experimental data in Fig. 3, the following form of creep equation

$$
\varepsilon_{p}=717 E-6 \sigma^{1.85} \mathrm{e}^{0.021 T} \tau^{0.209} .
$$

Graphically, function (11) for selected parameters $\sigma, T$ were presented on Figs. 4-6.

Figure 7 presents overall creep characteristic of wires under the conditions of stress decrease by the given value $\Delta \sigma$, performed after an hour primary creep process.

The obtained results clearly confirm the hypothesis of intensity decrease and even temporary stop of creep process under the conditions of negative stress gradient. A detailed 

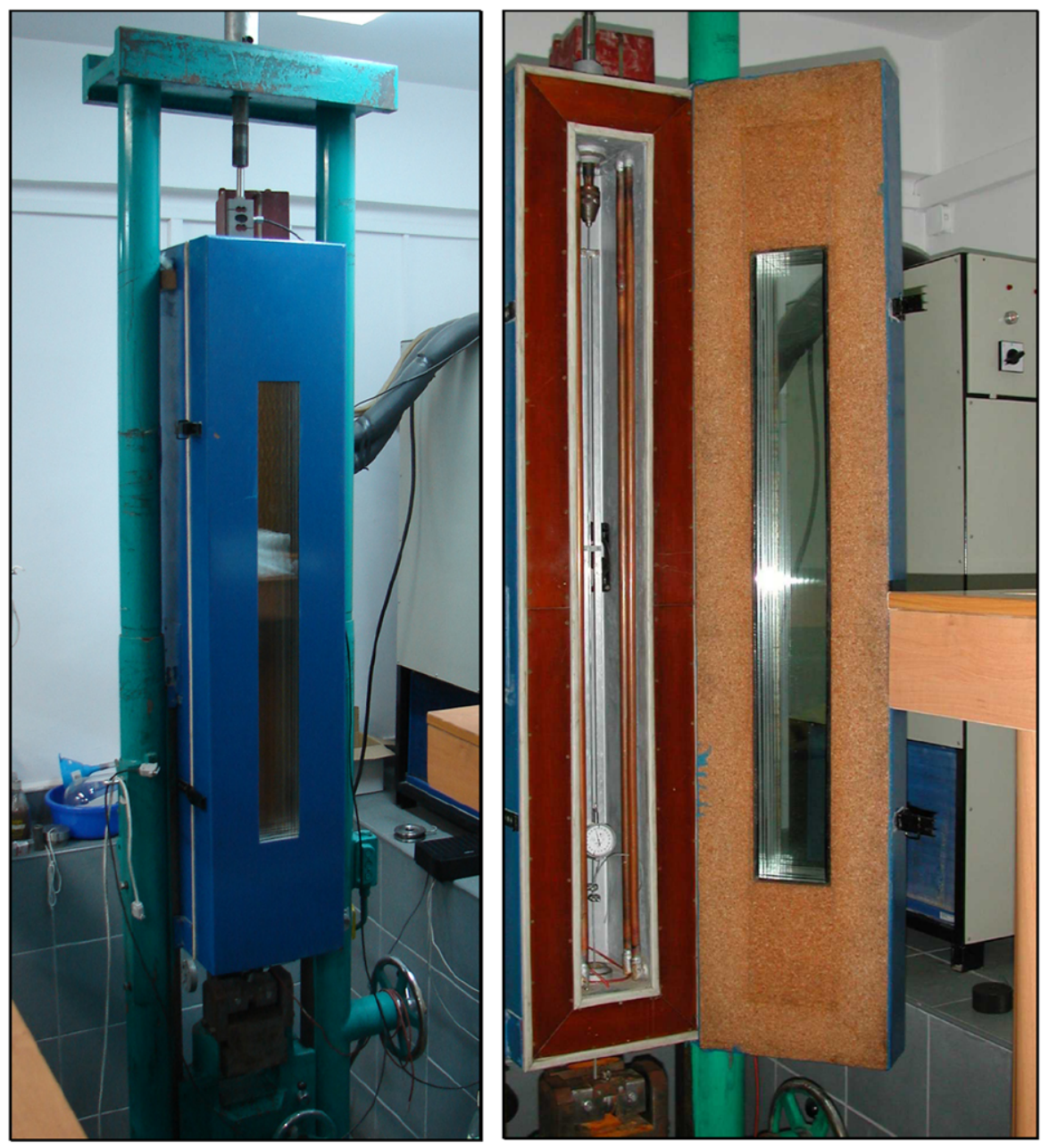

Fig. 2 Wires creep test stand

analysis of the diagrams above allows for the differentiation of three types of material rheological behaviour, directly after load decrease, and these are:

Type 1-Temporary decrease of creep speed (curve A)

Type 2-Temporary stop of creep deformation (dead time) (curves $B, C$ )

Type 3-Reverse after creep (curve D).

Types 1 and 2 are the domain of small stress gradients, whereas reverse after creep (type 3) requires respectively substantial stress decrease. On the basis of performed tests, it is stated that e.g. stress decrease by $6 \mathrm{MPa}$ from $136 \mathrm{MPa}$ (being approx. $4 \%$ of initial stress) does not result in dead time, yet causes only $\beta$ modulus change of creep function dependent on primary creep duration and in such a way as with time increase, $\beta$ modulus of secondary creep function reach the primary value of 0.209 . Characteristics presented on Figs. 8-10 illustrate that observation. On their basis, it can be assumed that with the proceeding creep 


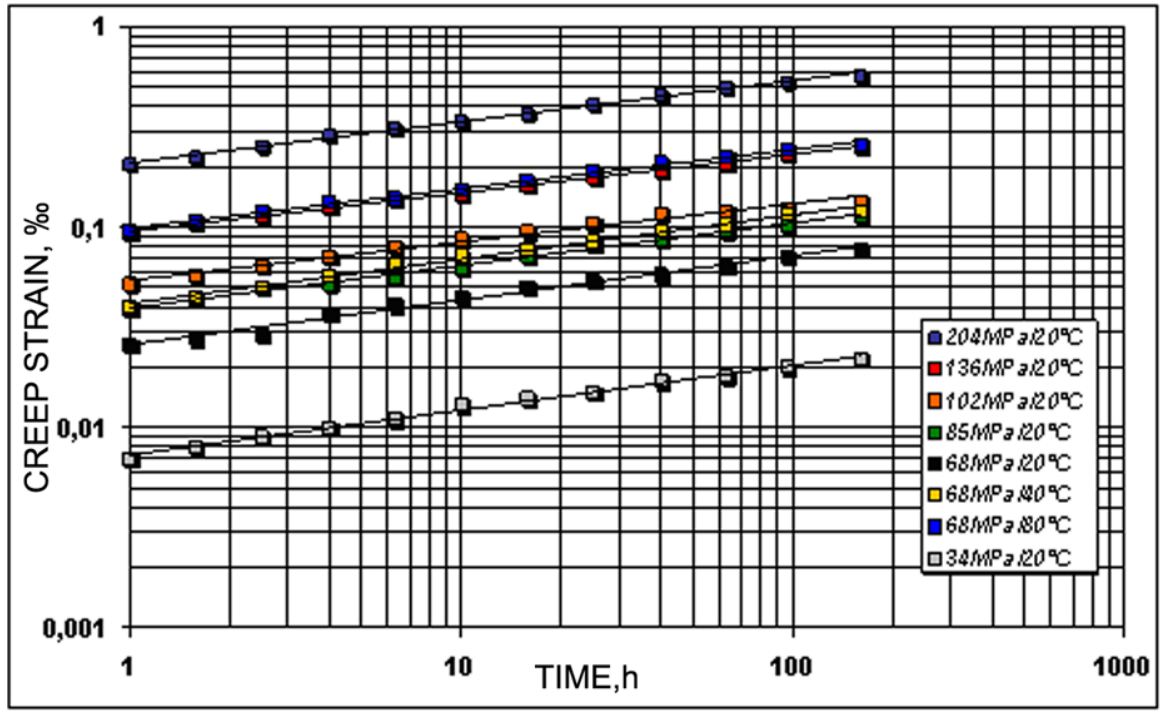

Fig. 3 Creep characteristics of AlMgSi wires in various stress and temperature conditions (Smyrak 2006)

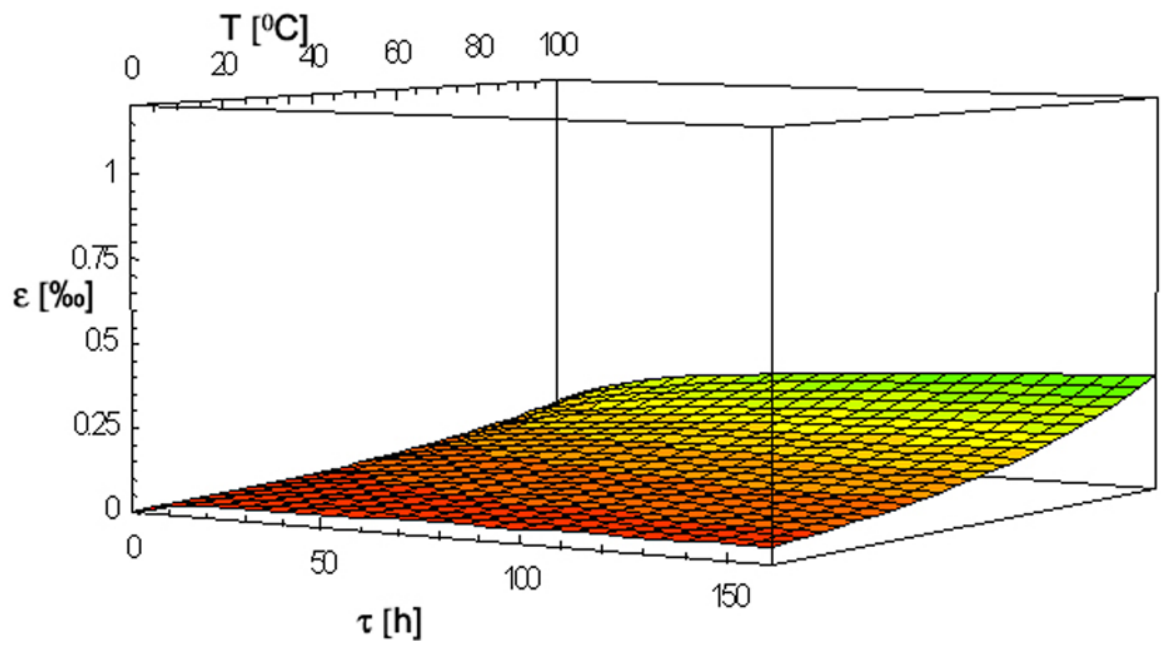

Fig. 4 The overall creep function of AlMgSi wire-68 MPa (20\%UTS)

process, small stress decreases lead to neither activity stop nor creep process characteristic change (Fig. 8).

The increase of stress decrease value - according to results presented in Figs. 9 and 10 results in longer phases of rheological inactivity, of even up to 300 hours and at the same time in deepening of reverse effect after creep, which can entirely dominate rheological inactivity period (cf. Fig. 10).

We can notice that the necessary condition for rheological inactivity phase occurrence is coercion of respectively substantial stress decrease. In other words, there is some critical stress gradient, which is incapable of causing material rheological inactivity state. Its value 


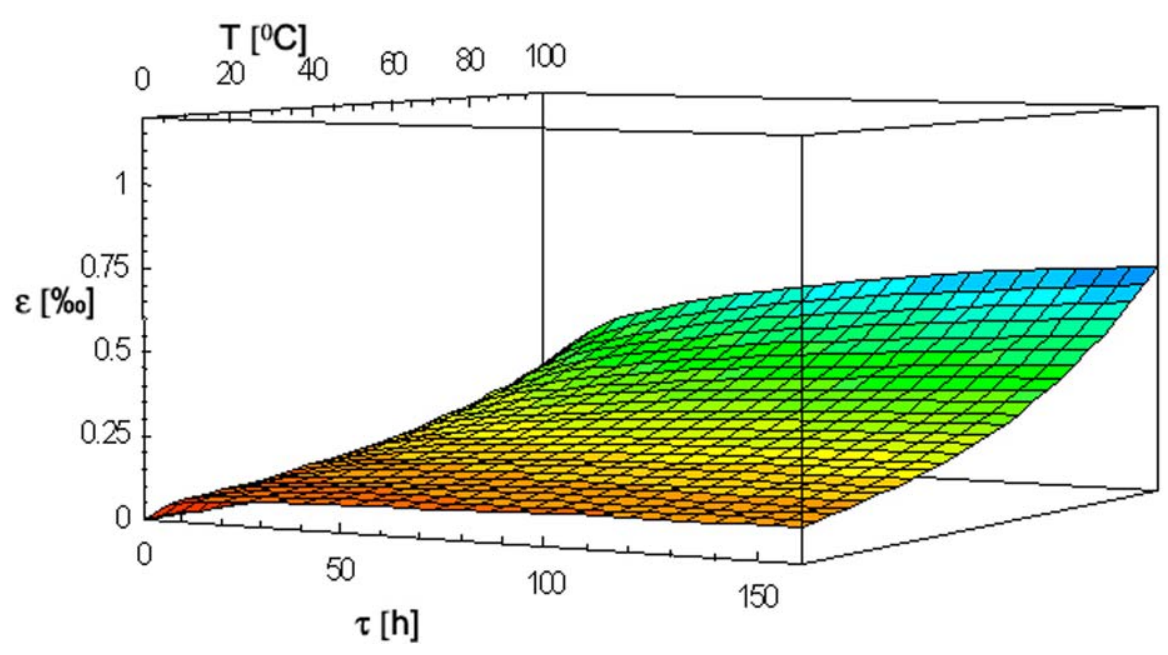

Fig. 5 The overall creep function of AlMgSi wire-100 MPa (30\%UTS)

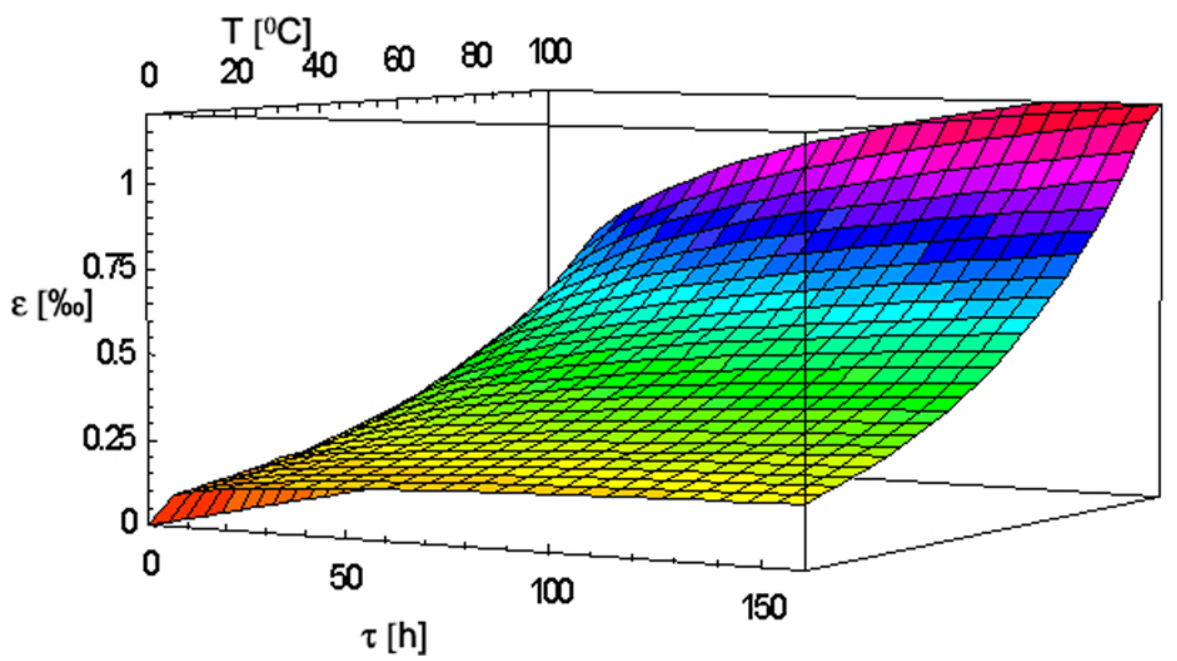

Fig. 6 The overall creep function of AlMgSi wire-136 MPa (40\%UTS)

depends on percentage level of stress decrease in relation to initial stress value. The values of critically negative stress gradients for alloy wires are presented in Table 5.

Analysing this problem from the point of view of exploitation of conductors hanged on spans of overhead power lines, especially, taking into account limitations of unfavourable creep phenomenon, it is clear that there exists tendency to transfer material into rheological inactivity state. Therefore, the second important factor, which should be accounted for during problem analysis, is duration of dead times. It depends on stress decrease value. In Table 6 there are dead time durations depending on stress gradient value, determined experimentally and calculated on the basis of ageing hypothesis and overall creep function (11). Figure 11 presents graphically the above mentioned relations. 


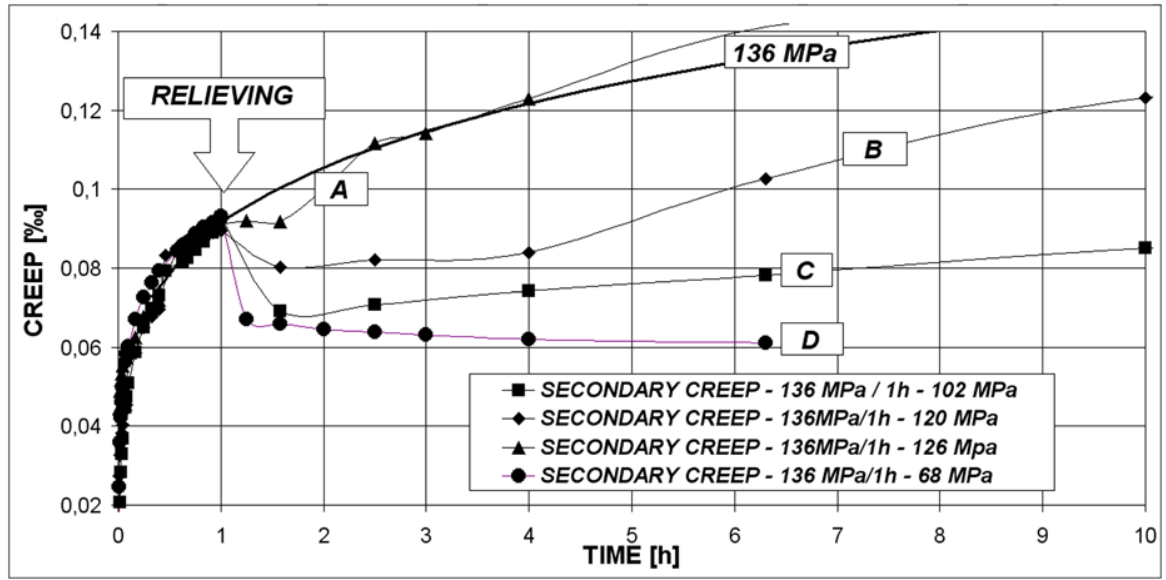

Fig. 7 Wires creep characteristics in various stress conditions

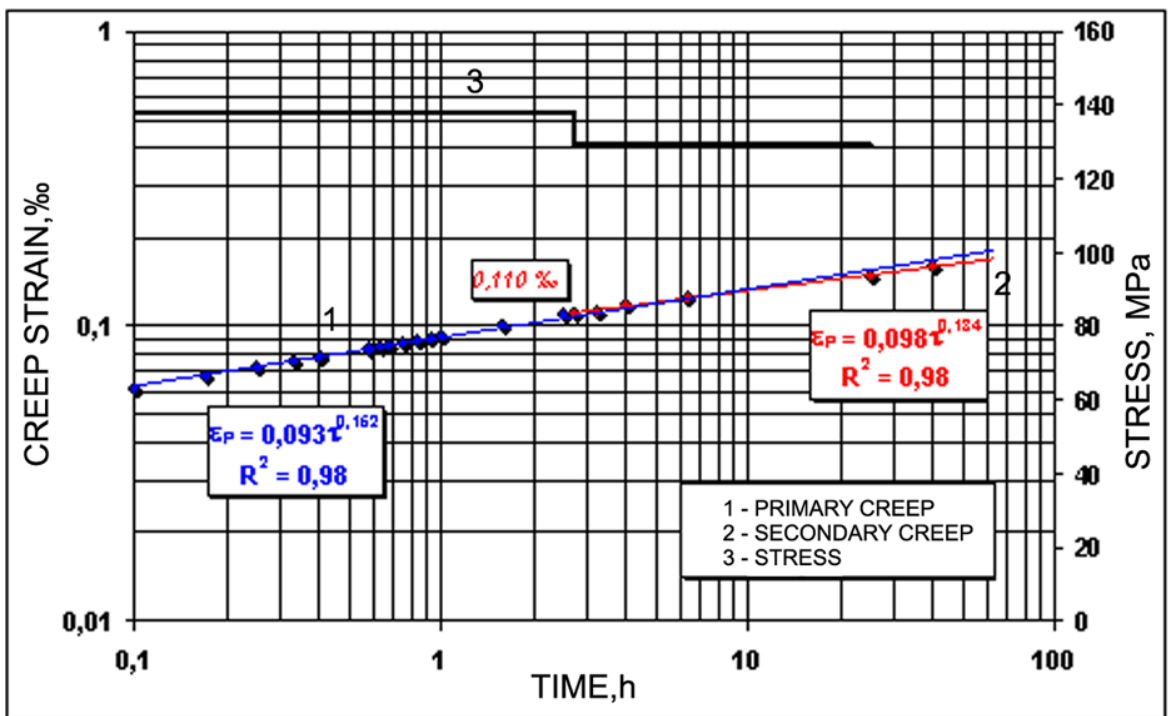

Fig. 8 Creep characteristics in trend of rapid stress decrease. Primary creep: $136 \mathrm{MPa} / 2.5 \mathrm{~h}$, secondary creep: $130 \mathrm{MPa}$

According to data on Fig. 11, it is noticeable that characteristics linearise in logarithmical system, thus we can state that rheological inactivity phase duration is power function of relation $\frac{\sigma_{1}}{\sigma_{2}}$ in the form of:

$$
\tau_{M}=0.95\left(\frac{\sigma_{1}}{\sigma_{2}}\right)^{8.65}
$$

where:

$\sigma_{1}$ - primary creep stress

$\sigma_{2}$ - secondary creep stress. 


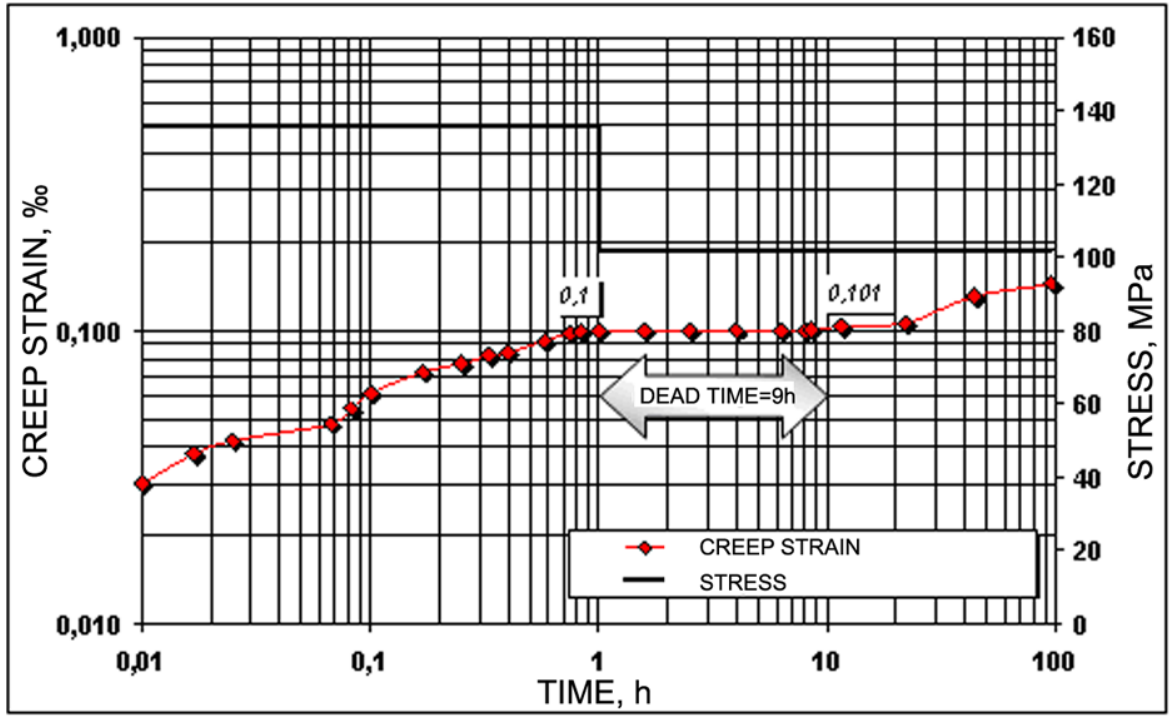

Fig. 9 Creep characteristics in trend of rapid stress decrease. Primary creep: $136 \mathrm{MPa} / 24 \mathrm{~h}$, secondary creep: $102 \mathrm{MPa}$. Duration of dead time-9 h

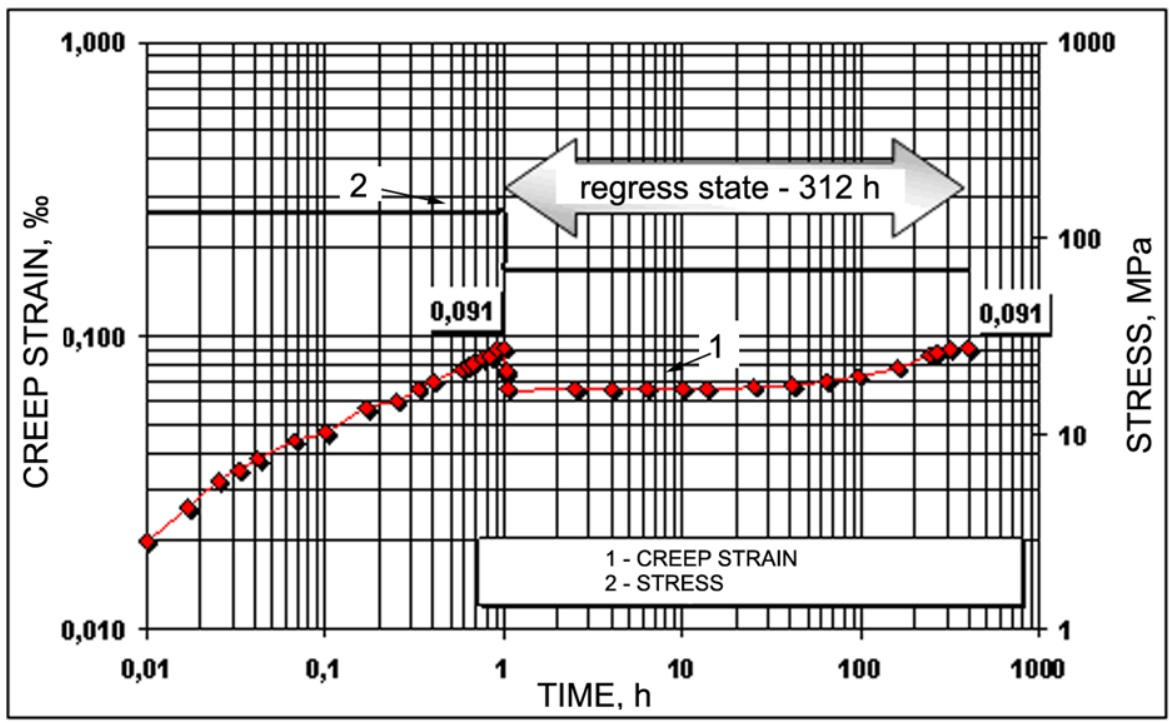

Fig. 10 Creep characteristics in trend of rapid stress decrease. Primary creep: $136 \mathrm{MPa} / 1 \mathrm{~h}$, secondary creep: $68 \mathrm{MPa}$. Duration of regress state-312 h

The parameters of the above relation correlate well with values determined on the basis of (5), the form of which was converted to the equation enabling determination of dead time 
Table 5 Type of the rheological behaviour after change of stress

\begin{tabular}{ll}
\hline$\Delta \sigma[\%]$ & Type of the rheological behaviour after decrease stress \\
\hline 4 & Temporary decrease of creep speed \\
$4-25$ & Temporary stop of creep deformation ('dead' time) \\
$>25$ & Reverse after creep \\
\hline
\end{tabular}

Table 6 Duration of the dead time

\begin{tabular}{|c|c|c|c|c|c|c|c|}
\hline \multicolumn{3}{|c|}{ Primary creep } & \multicolumn{3}{|c|}{ Secondary creep } & \multicolumn{2}{|c|}{ Duration of "dead time" } \\
\hline $\begin{array}{l}\sigma_{1} \\
{[\mathrm{MPa}]}\end{array}$ & $\begin{array}{l}\sigma_{1} \\
{[\% \mathrm{Rm}]}\end{array}$ & $\begin{array}{l}\tau_{1} \\
{[\mathrm{~h}]}\end{array}$ & $\begin{array}{l}\sigma_{2} \\
{[\mathrm{MPa}]}\end{array}$ & $\begin{array}{l}\sigma_{2} \\
{[\% \mathrm{Rm}]}\end{array}$ & $\sigma_{1} / \sigma_{2}$ & $\begin{array}{l}\tau_{M \_} \_ \text {THEORETICAL } \\
\text { (ageing hypothesis) }\end{array}$ & $\tau_{M \_ \text {EXPERIMENT }}$ \\
\hline 136 & 40 & 1 & 68 & 20 & 2.0 & 461 & 312 \\
\hline 136 & 40 & 1 & 85 & 25 & 1.6 & 63 & 50 \\
\hline 136 & 40 & 1 & 102 & 30 & 1.3 & 11.8 & 9 \\
\hline 136 & 40 & 1 & 120 & 35 & 1.1 & 2 & 1 \\
\hline 136 & 40 & 1 & 130 & 38 & 1.0 & 0.2 & $\sim$ \\
\hline
\end{tabular}

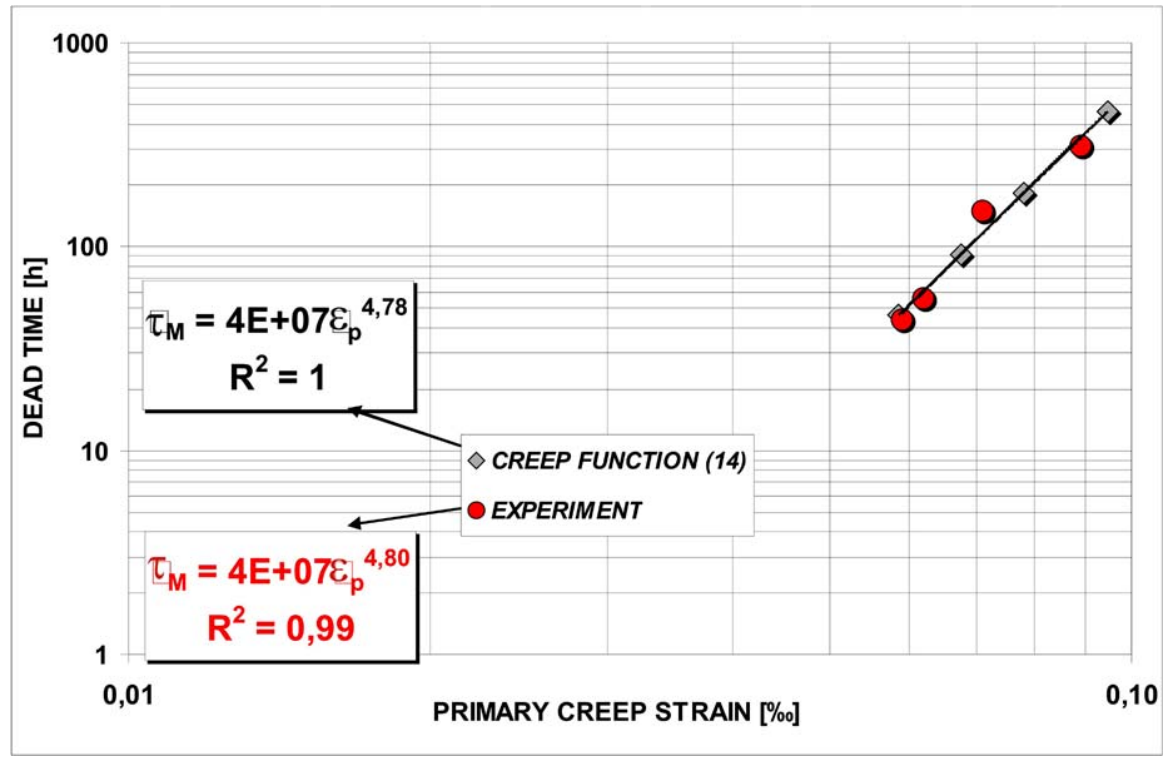

Fig. 11 Duration of the dead time value as a function of stress change degree

duration $\tau_{M}$, is presented in the formula of:

$$
\tau_{M}=\tau_{2}-\tau_{1}=\tau_{2}\left(\left(\frac{\sigma_{1}}{\sigma_{2}}\right)^{\frac{n}{\beta}}-1\right) .
$$

For the creep function expressed by (11), the value of the relation $n / \beta=8.88$, and it is consistent with the value $n / \beta=8.65$, determined experimentally (cf. (12)). The analysis of 
Table 7 Rheological inactivity duration phases values for various primary creep duration

\begin{tabular}{lll}
\hline $\begin{array}{l}\tau_{P} \\
{[\mathrm{~h}]}\end{array}$ & $\begin{array}{l}\tau_{M}(\mathrm{UFP}) \\
{[\mathrm{h}]}\end{array}$ & $\begin{array}{l}\tau_{M} \text { (exp.) } \\
{[\mathrm{h}]}\end{array}$ \\
\hline 0.1 & 46.1 & 44 \\
0.2 & 92.0 & 56 \\
0.4 & 184.0 & 160 \\
1 & 461 & 314 \\
\hline
\end{tabular}

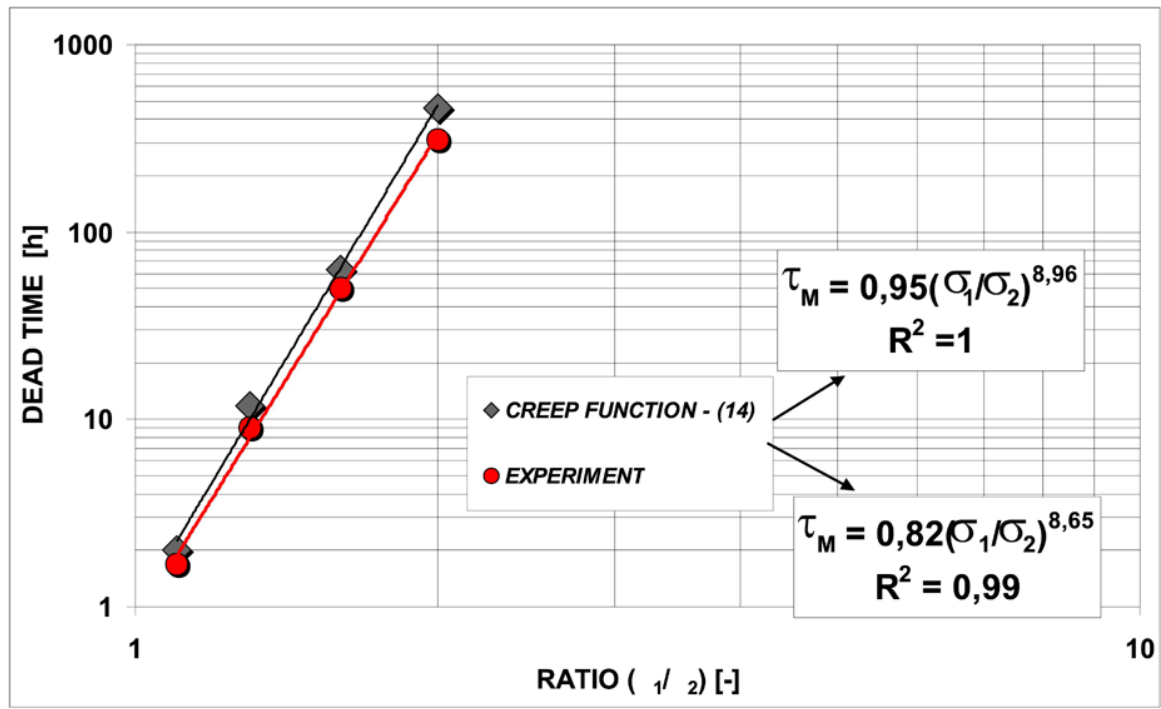

Fig. 12 Value of dead time duration as a function of primary creep deformation $\tau_{M}-\varepsilon_{p} \_$primary

experimental tests results from the point of view of rheological inactivity phase duration, apart from unquestionable influence of negative gradient value, must include primary creep duration or primary creep deformation value. The higher primary creep deformation value, the longer is dead times duration. Table 7 includes rheological inactivity duration phases values for various primary creep duration (various primary creep deformation value).

On the basis of data from Table 7 and characteristics presented on Fig. 12, we can notice that experimental relation $\tau_{M}-\varepsilon_{p \_ \text {pierwotne }}$ is power function of

$$
\tau_{M}=4 \cdot 10^{7} \varepsilon_{p \_ \text {primary }}^{4.80} .
$$

Whereas data determined on the basis of (11) is

$$
\tau_{M}=4 \cdot 10^{7} \varepsilon_{p \_ \text {primary }}^{4.78} .
$$

The preformed analysis of test results demonstrates clear influence of stress negative gradient values and primary creep deformation on character and duration of rheological inactive phase. It is worth mentioning here that experimentally determined dead time durations after abrupt load change correlate quite well with values set theoretically on the basis of overall creep function on the basis of Robotnov's ageing hypothesis. The idea of the hypothesis 


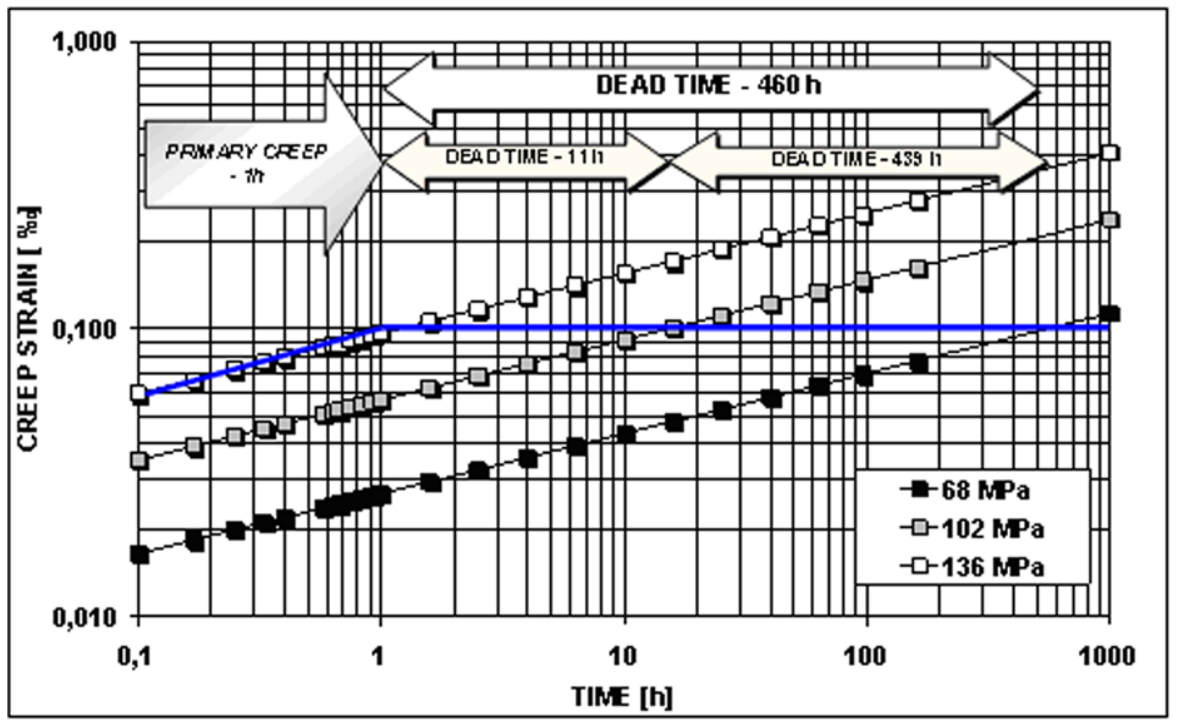

Fig. 13 Estimate of dead time duration using ageing hypothesis-(11)

is illustrated in Fig. 13, on which dead times duration after primary creep under stress of $136 \mathrm{MPa}$ in one hour and then after load decreases to respectively 102 and $68 \mathrm{MPa}$ were presented.

The obtained compatibility of experimental result with calculations performed according to Rabotnov's ageing hypothesis proves the correctness of adopted algorithm idea to calculate dead times. However there may be doubts as far as correctness is concerned due to the fact that creep isochors are non-linear (cf. Fig. 14), which indicated that the tested material is not a body in the strict Boltzman sense. The calculation algorithm adopts the isochors unit linearisation, what for long spans introduces insignificant reverse from the practical point of view.

\section{Short application}

The increasing demand on power supplies in the whole world requires search for new optimal solution of the possibilities to dynamically steer line's current carrying capacity. Therefore, there is the need to create model describing mechanical-rheological-thermal reaction of hanged conductor on its changeable operational conditions.

We will consider the case in which stress changes in conductor took place in real temperature conditions. Stress change in conductor is then the result of superposition of two material's reactions on temperature change. The first one-irreversible changes of conductor length resulting from its temperature change, the second one-permanent increases of conductor length of creep origin. Let's assume that conductor made of AlMgSi alloy wires with rheological equivalent $n / \varphi=88 \mathrm{~K}$ is hanged on span of 400 meters. Assembly was carried out in April under the following conditions: $T_{m}=10^{\circ} \mathrm{C}, \sigma_{m}=91.4 \mathrm{MPa}$. Figure 15 presents stress change in conductor in time for given weather conditions. However on the Figure there are two stress change characteristics: 1-determined traditionally from conductor hanged state conditions equation, excluding material rheological nature and 


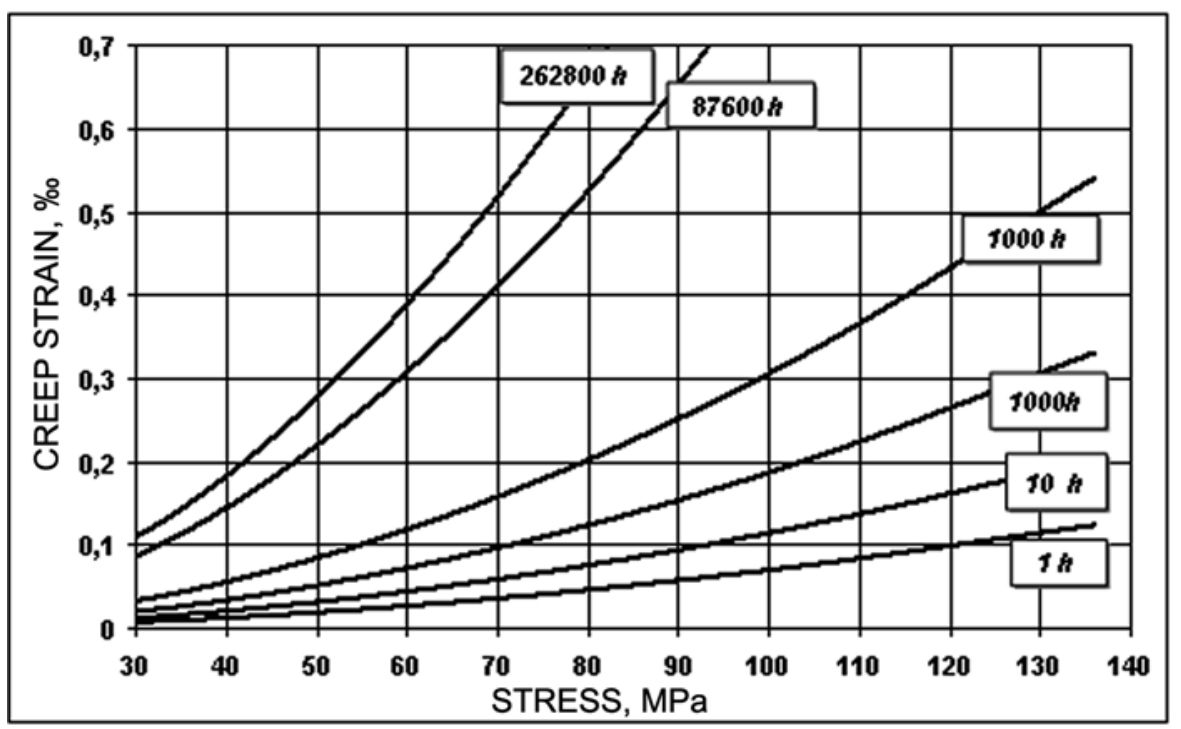

Fig. 14 The isochors according to (11)

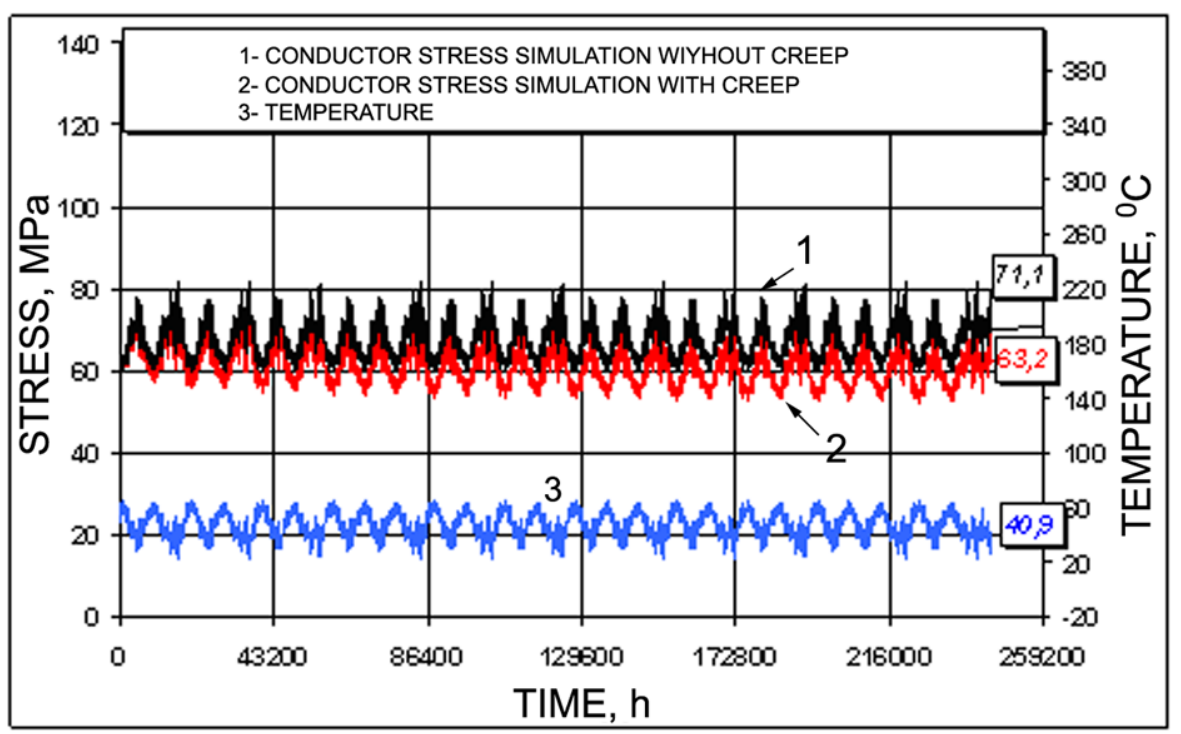

Fig. 15 Stress change simulation in conductors from AlMgSi over a period of 10 years with and without creep process, $a=400 \mathrm{~m}, n / \phi=88 \mathrm{~K}$

2-which illustrates stress changes determined on the basis of algorithm including creep process. Figure 16 presents conductor creep characteristics under the conditions of permanent and changeable stress with clearly marked rheological inactive phases, arising after stress decrease. The estimated difference of a 30-year creep value is approx 0.3 per mille, and estimated total creep time is approx. 16 years, i.e. $40 \%$ of conductor service life. 


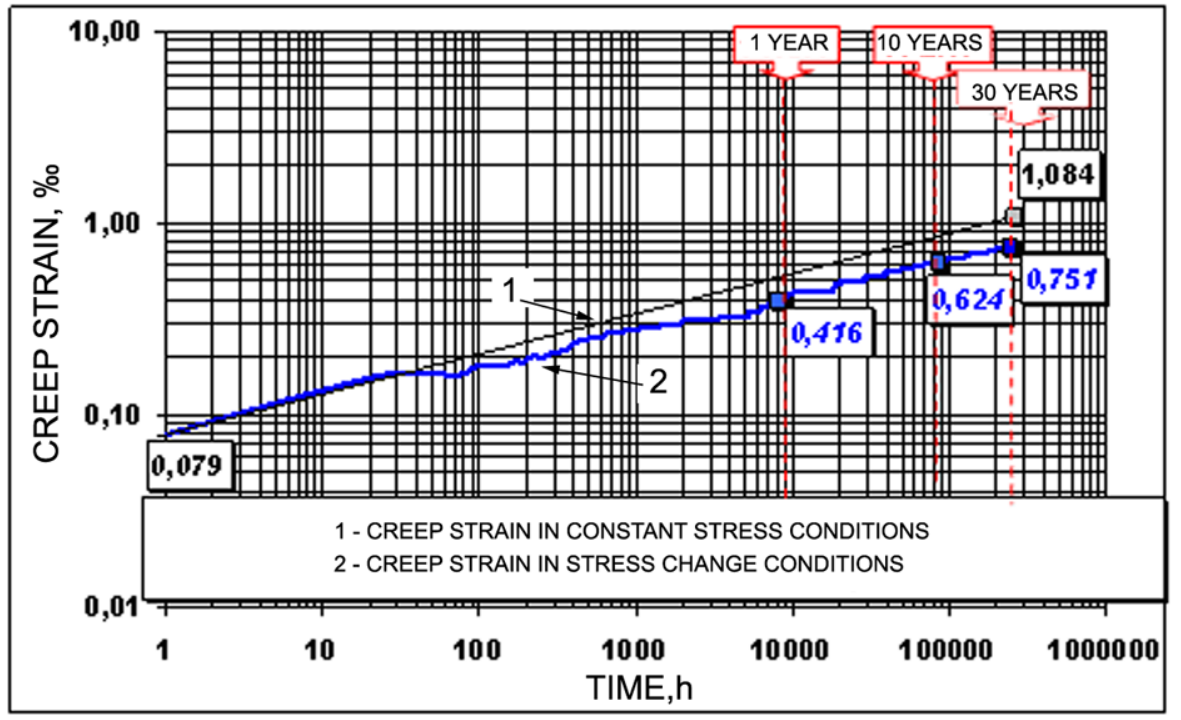

Fig. 16 Creep characteristics under the conditions of permanent and changeable stress

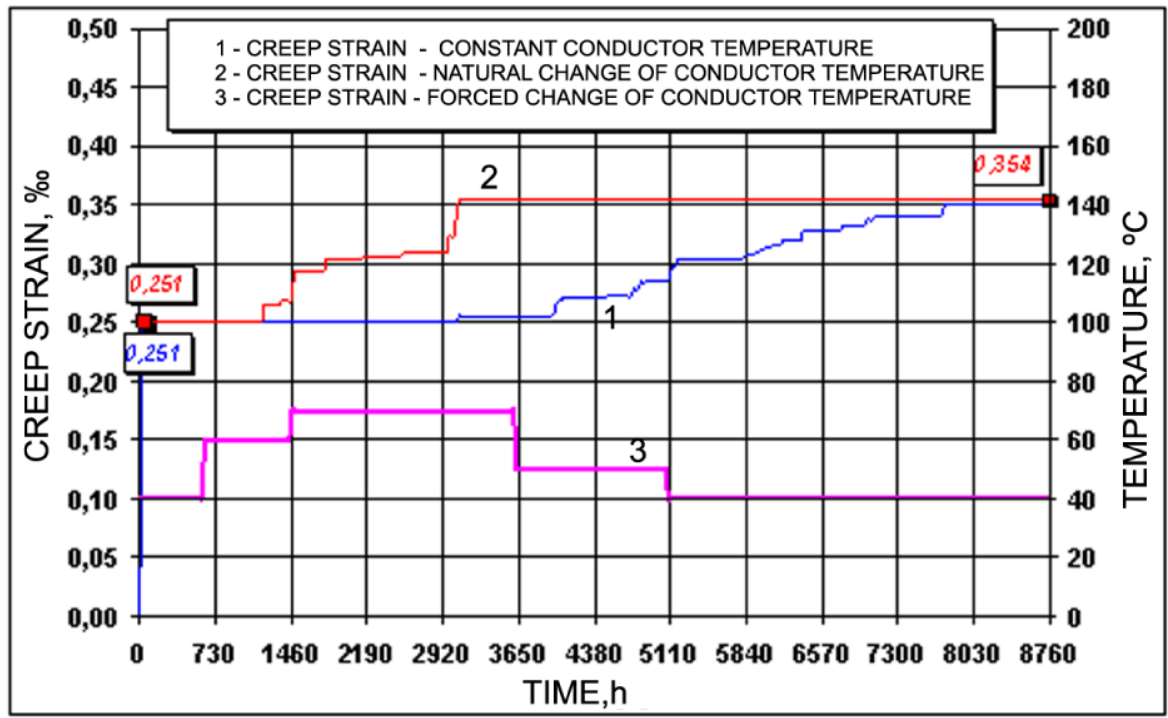

Fig. 17 Creep characteristics under the conditions of permanent and changeable stress$136 \mathrm{MPa} / 24 \mathrm{~h}-70 \mathrm{MPa}$ in various temperature conditions

Possible use of rhetorical inactive phases, created as a result of stress decrease, may become essential from the point of view of practical methods of creep process elimination by the simultaneous increase of the amount of transferred current. In Fig. 17 there are two characteristics of conductor creep after overstressing from $136 \mathrm{MPa} / 24 \mathrm{~h}$ to $70 \mathrm{MPa}$, with the 1 characteristic presenting creep in conditions of fixed conductor temperature of $40^{\circ} \mathrm{C}$ plus 
temperature of the environment. The 2 characteristic was created as a result of equivalent exchange of stress gradient $66 \mathrm{MPa}(136-70)$ due to conductor temperature increase up to $70^{\circ} \mathrm{C}$. We can notice that as a result of temperature changes the dead time shortened slightly. The return of the conductor into the state of rheological inactivity is possible after applying temperature of $70^{\circ} \mathrm{C}$ and withholding it, and then its gradual decreasing. It is illustrated by a step-like segment of conductor temperature characteristics.

\section{Conclusions}

1. It has been experimentally proved that negative stress gradients lead to a stop of creep process of AlMgSi alloy wires.

2. Three ways of material behaviour after application of negative stress gradient during creep process have been recognised:
a. Temporal decrease of creep process speed
b. Temporal creed deformation stop called dead time
c. Further decrease of deformation after unloading called reverse

3. AlMgSi alloy conductor can be treated as linear- visco-elastic body

4. Alloy conductor creep under the conditions of changeable stress may be approximated by Robotnov's ageing hypothesis.

5. Material rheological inactive states may be used to dynamically steer conductor current carrying capacity, what enables to increase transfer power of transfer lines.

Open Access This article is distributed under the terms of the Creative Commons Attribution Noncommercial License which permits any noncommercial use, distribution, and reproduction in any medium, provided the original author(s) and source are credited.

\section{References}

Andrade, E.N. da C.: On the viscous flow of metals and allied phenoma. Proc. R. Soc. 84(A567) (1910)

Boltzman, L.: Zur Theorie der elastischen Nachwirkung. Pogg. Ann. Physik (1876)

Bradbury, J., Dey, P., Orawski, G., Pickup, K.H.: Long-term-creep assessment for overhead line conductor. Proc. IEEE R 122(10) (1975)

Cadek, J.: Creep in Metallic Materials. Academia Prague, Prague (1988)

Garofalo, F.: Fundamentals of Creep and Creep-Rupture in Metals. MacMilan, New York (1965)

Harvey, J.R.: Creep of transmission line conductors. IEEE Trans. Power Apparatus Syst. Pas-88(4) (1960)

Harvey, J.R., Larson, R.E.: Use of elevated-temperature creep data in sag-tension calculations. IEEE Trans. Power Apparatus Syst. Pas-89(3) (1970)

IEC: Overhead electrical conductors-calculation methods for stranded bare conductors (1597-1995)

Lubahn, J.D., Felger, R.P.: Plasticity and Creep of Metals. Wiley, New York/London (1961)

Norton, F.H.: The Creep of Steel at High Temperature. McGraw-Hill, New York (1929)

Odqvist, F.K.G.: Mathematical Theory of Creep and Creep Rupture. Clarendon Press, Oxford (1966)

Penny, R.K., Marriott, D.L.: Design for Creep. MacGraw-Hill, London (1971)

Rabotnov, Y.N.: Кратковременная ползучесть. Wyd. Nauka, Moskwa (1970)

Roest, A.: Creep studies of aluminum conductor alloys. IEEE Trans. Power Apparatus Pas-89(11) (1969)

Sandell, D.H.: Sags and tensions of overhead conductors. Aluminium Company of America (1961)

Smyrak, B.: The analysis of stress and temperature characteristics of a overhead electroenergetic conductors from alloys AlMgSi. Ph.D. Thesis, Department on Nonferrouse of Metals, University od Science and Technology-AGH, Kraków (2006)

Smyrak, B., Knych, T., Mamala, A.: Rheological inactivity of AlMgSi conductor alloys in trend of negative stress and temperature gradients. ECCC Creep Conference, September 12-14, 2005, London, UK, DEStech Publications, Inc. (2005)

Wood, A.B.: A practical method of conductor creep determination. Electra (October 1972) 